\title{
Embroidered Confessions
}

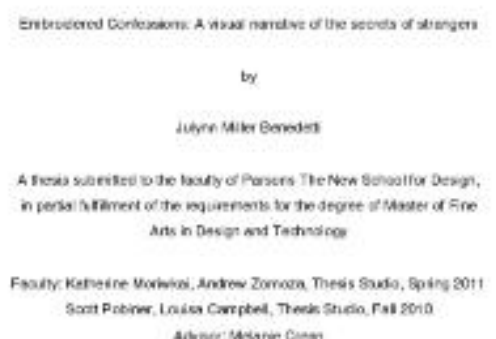

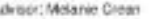

Diess probetion wasate.

mentemeatess

\section{Related Collection}

2011 (PC020402.10) $\rightarrow$ Parsons School of Design MFA Design and Technology program theses

\section{Description}

Embroidered Confessions is a visual narrative in the form of an interactive quilt that collects and curates the secrets of strangers from across the Internet. The shelf-life of digital information such as tweets, Facebook status updates and blog posts is fleeting. They seem to exist for a moment, then disappear into our collective digital consciousness. However, in reality, information is constantly collected and stored on vast servers. Through the weaving of the stories and secrets of strangers from the Internet into a material artifact, Embroidered Confessions visualizes this duality of digital information.

\section{Date}

2011

\section{Related people}

Julynn Benedetti (designer)

Katherine Moriwaki (thesis advisor)

Page 1 of 2 
Andrew Zornoza (thesis advisor)

Scott Pobiner (thesis advisor)

Louisa Campbell (thesis advisor)

Melanie Crean (thesis advisor)

\section{Use Restrictions}

In accordance with The New School's Intellectual Property Rights Policy, copyright is held by each thesis' respective author. The responsibility to secure copyright permission rests with the user.; http://rightsstatements.org/vocab/lnC/1.0/

\section{Identifier}

PC020402_2011_jbenedetti 